\title{
Circum-Indian ocean hydroclimate at the mid to late Holocene transition: The Double Drought hypothesis and consequences for the Harappan
}

\section{Supplementary Information}

Nick Scroxton1,2,3*

Stephen J. Burns 1

David McGee2

Laurie R. Godfrey4

Lovasoa Ranivoharimanana5

Peterson Faina5
ORCID: 0000-0003-2315-9199

ORCID: 0000-0003-4623-5326

ORCID: 0000-0002-7329-3428

ORCID: 0000-0001-9997-0207

ORCID: 0000-0002-0393-2845

ORCID: 0000-0002-3851-6913

1 Department of Geosciences, 611 North Pleasant Street, University of Massachusetts Amherst, MA 01030, USA

2 Department of Earth, Atmospheric and Planetary Sciences, Massachusetts Institute of Technology, 77 Massachusetts Avenue, Cambridge, MA 02139, USA

3 current address: School of Earth Sciences, University College Dublin, Bellfield, Dublin 4, Ireland

4 Department of Anthropology, 240 Hicks Way, University of Massachusetts, Amherst, MA 01003, USA

5 Mention Bassins sédimentaires, Evolution, Conservation (BEC) - BP 906 - Faculté des Sciences, Université d'Antananarivo - 101 Antananarivo, Madagascar

Correspondence to: Nick Scroxton (nick.scroxton@ucd.ie)

\section{Contents:}

- Supplementary Table 1: Summary of all sites

- Supplementary Discussion 1: Chosen records and interpretation

- Supplementary Figure 1: Data treatment of paleoclimate records prior to principal component analysis 


\section{Supplementary Table 1: Summary of all sites}

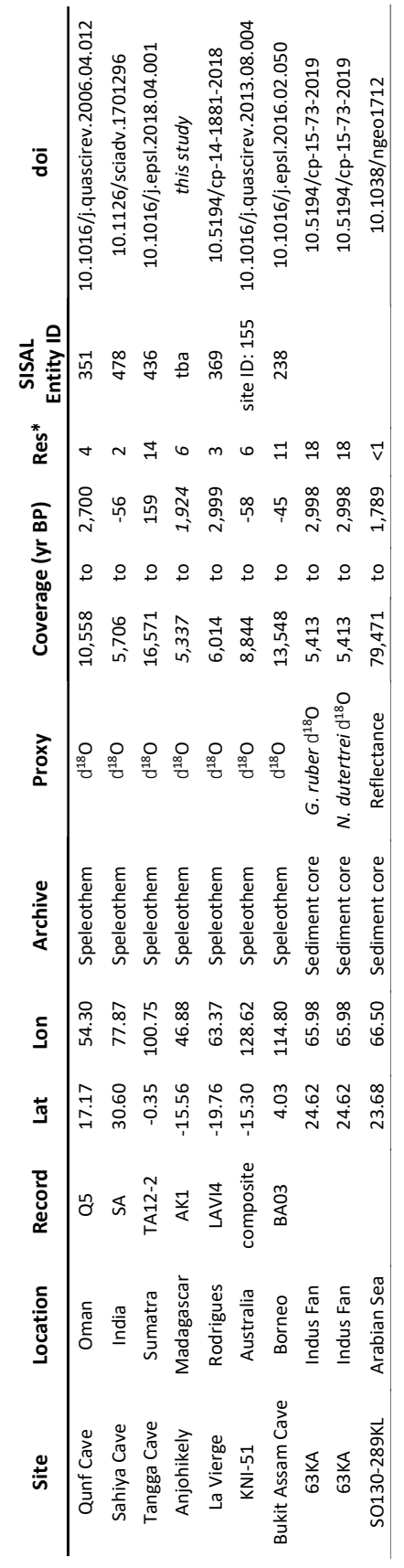




\section{Supplementary Discussion 1: Chosen records and interpretation}

To place the $4.2 \mathrm{kyr}$ event in high-resolution context, we restricted our analyses to speleothem records with coverage of 5000-3000 yrs BP, with sample resolution better than 15 years. All records had at least 2 U-Th ages in the 5000-3000 yrs BP interval, and up to 17. Two records, Australia and Madagascar, had small hiatuses which were filled with dummy $\delta^{18} \mathrm{O}$ data (Supplementary Figure 1).

Speleothem $\delta^{18} \mathrm{O}$ is frequently idiosyncratic, responding to the combination of regional climate dynamics, local rainfall and drip flow pathways in unique ways. However, the common signal of speleothems is widely interpreted as climatic in origin. In the tropics, most speleothem $\delta^{18} \mathrm{O}$ records are likely correlated to local and regional rainfall amount, even if the precise mechanism of $\delta^{18} \mathrm{O}$ variability is not exclusively the "amount effect". Speleothem $\delta^{18} \mathrm{O}$ and rainfall amount at Qunf cave in Oman are both controlled by the amount of orographic uplift of moisture, driven by changes in Indian Ocean monsoon strength and Inter-Tropical Convergence Zone position (Fleitmann et al., 2003). At Sahiya Cave in western India, speleothem $\delta^{18} \mathrm{O}$ is interpreted as recording variations in the Indian Summer Monsoon strength via changes in upstream circulation (Kathayat et al., 2017), i.e. spatially integrated rainfall amount and source moisture changes. Speleothem $\delta^{18} \mathrm{O}$ from TA12-2 from Tangga Cave, Sumatra, responds to a combination of regional rainfall amount and source moisture effects, with variability driven by changes in moisture source and amount from the eastern Indian Ocean (Wurtzel et al., 2018). Stalagmite AK1 from Anjohikely in northwestern Madagascar is presented in this paper. As a low altitude coastal site previous studies from Anjohikely and nearby Anjohibe have interpreted stalagmite $\delta^{18} \mathrm{O}$ as proxies for rainfall amount and summer monsoon strength with a strong rainshadow limiting the influence of non-wet season moisture and changes in source (Scroxton et al., 2017; Voarintsoa et al., 2019; Wang et al., 2019). As a tropical oceanic site, stalagmite $\delta^{18} \mathrm{O}$ at Rodrigues is likely almost exclusively controlled by local rainfall amount. $\delta^{18} \mathrm{O}$ variability is attributed to both large scale zonal and meridional atmospheric circulation changes and smaller local effects (Li et al., 2018). Stalagmite $\delta^{18} \mathrm{O}$ at KNI-51 in northwestern Australia are also interpreted as almost purely summer monsoonal strength, highly correlated with local rainfall amount and with limited ability to change moisture source. Variability in $\delta^{18} \mathrm{O}$ through the Holocene is attributed to both meridional and zonal circulation changes (Denniston et al., 2013).

We also include the stalagmite record BA03 from Borneo as an out-of-Indian Ocean comparison record. Speleothem $\delta^{18} \mathrm{O}$ is interpreted as an amount-weighted average of rainwater $\delta^{18} \mathrm{O}$ in the preceding 3-10 months (Moerman et al., 2014), tracking changes in regional hydroclimate and showing sensitivity to ENSO variation at multiple timescales (Carolin et al., 2013; Chen et al., 2016; Partin et al., 2007).

Additional speleothem records from the circum-Indian Ocean basin which are not included in this analysis include records from Liang Luar, Flores, Indonesia (Griffiths et al., 2009); Mawmluh Cave, India (Berkelhammer et al., 2012; Kathayat et al., 2018); and Sainji cave India (Kotlia et al., 2015). At Liang Luar stalagmite LR06-B3 has a hiatus from 3.7kyr BP, while a continuous stalagmite LR06-B1 is of low resolution. From Mawmluh Cave, India, stalagmite KM-A stops growing at 3.65 kyr BP, ML.1 at 3.78 and ML.2 at 3.36 kyr BP. At Sainji cave, 
stalagmite SA-1 only starts growing at 4.0 kyr BP. We also do not include speleothems from China, which are subject to a wide variety of climatic influences (Hu et al., 2019).

In later analyses the speleothem records are supplemented with three marine sediment core records from two cores, both with laminations and greater than 20 -year sample resolution. The Arabian Sea sediment reflectance record measures changing terrigenous versus biogenic content and is interpreted as recording Indian summer monsoon strength through changing runoff (Deplazes et al., 2013). Two foraminifera records from a laminated sediment core 63KA from close to the Indus river are interpreted as proxies for runoff from the Indus. The surface-dwelling Globigerinoides ruber $\delta^{18} \mathrm{O}$ record is interpreted as measuring changes in sea-surface salinity due to variations in discharge from the Indus, biased towards the summer months with possible but minor influence from winter discharge (Giesche et al., 2019). The thermocline dwelling Neogloboquadrina dutertrei $\delta^{18} \mathrm{O}$ record is interpreted as reflecting winter water column mixing through the homogenization or stratification of the water column through strong or weak winter monsoon winds (Giesche et al., 2019). 


\section{Supplementary Figure 1: Data treatment of paleoclimate records prior to principal}

component analysis
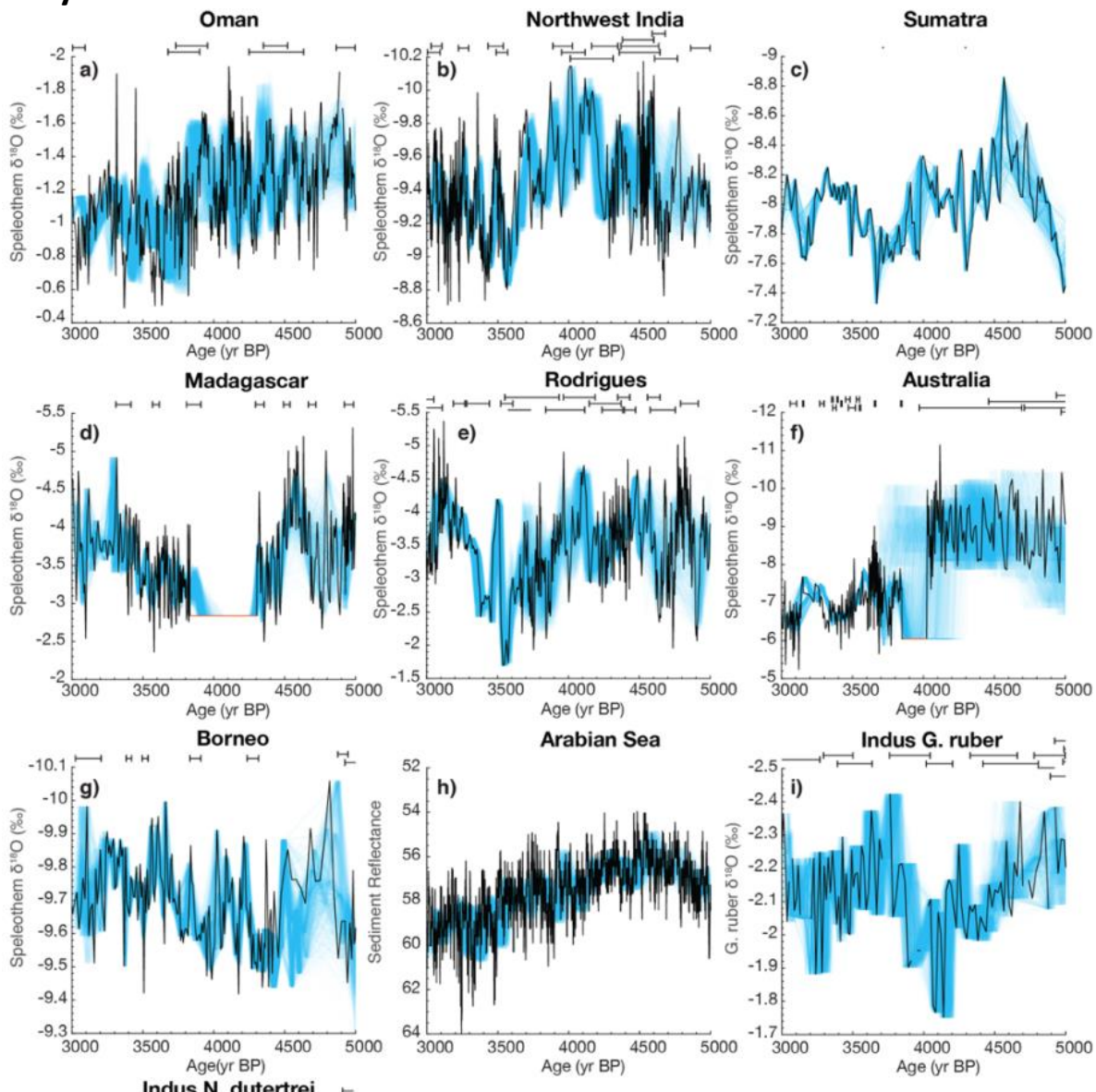

Arabian Sea
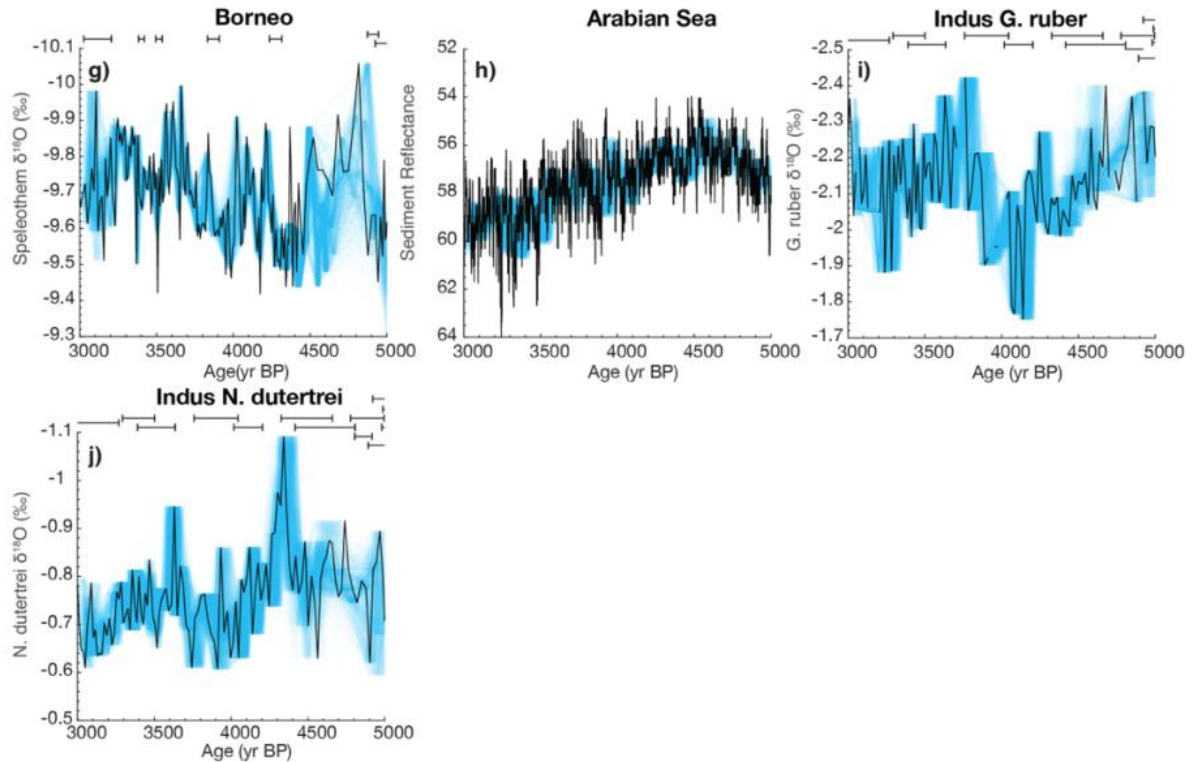

Supplementary Figure 1: Stable isotope time series used in principal component analysis. Black lines indicate original time series. Blue lines show the 2000 time series generated by the MC-PCA for each time series, using Gaussian distribution of ages and linear interpolation. Orange lines $(d, f)$ indicate periods of dummy d180 values to bridge gaps during short hiatuses. 